\title{
Membrane and Soluble Forms of Endoglin in Preeclampsia
}

Barbara Oujo $^{1,2,3}$, Fernando Perez-Barriocanal ${ }^{1,2,3}$, Carmelo Bernabeu ${ }^{4}$ and Jose M. Lopez-Novoa ${ }^{*, 1,2,3}$

${ }^{1}$ Renal and Cardiovascular Research Unit, Department of Physiology and Pharmacology, University of Salamanca, 37007 Salamanca, Spain

${ }^{2}$ Biomedical Research Institute of Salamanca (IBSAL), 37007 Salamanca, Spain.

${ }^{3}$ Institute Queen Sophie for Renal Research (IRSIN), Fundación Renal Iñigo Alvarez de Toledo, 37007 Salamanca, Spain

${ }^{4}$ Centro de Investigaciones Biológicas, Consejo Superior de Investigaciones Científicas (CSIC), Centro de Investigación Biomédica en Red de Enfermedades Raras (CIBERER), 28040 Madrid, Spain

Address correspondence:

Jose M. Lopez-Novoa, Department of Physiology and Pharmacology; University of Salamanca, Edificio Departamental, Campus Miguel de Unamuno, 37007 Salamanca, Spain; Tel: +34 923294472; Fax: +34 923294669; E-mail: jmlnovoa@usal.es 
Preeclampsia is a disease of high incidence in pregnant women which complicates pregnancy and may lead to the death of mother and baby. Preeclampsia is characterized by a series of clinical features such as hypertension and proteinuria associated with endothelial dysfunction. Although the causes of disease have not been elucidated, it has been reported that high levels of endoglin, a TGF-beta auxiliary co-receptor, and a soluble form of this protein, occur respectively in the placenta and plasma of women who develop the disease. In this review, the alterations in vasculogenesis and angiogenesis that occur during preeclampsia, the cellular and molecular mechanisms that lead to increased membrane bound endoglin expression and soluble endoglin release, including hypoxia and oxidative stress, and the possible pathogenic role of soluble endoglin in this disease have been analyzed.

Keywords: Endoglin, endothelial dysfunction, hypertension, hypoxia, oxidative stress, placenta, preeclampsia, soluble endoglin. 


\section{INTRODUCTION}

Preeclampsia is a pathology which affects between 3 and $5 \%$ of pregnant women worldwide, being one of the first causes of maternal-fetal mortality and morbidity [1]. This illness is characterized by the appearance, in the third trimester of pregnancy, of hypertension (systolic arterial pressure $>140$ $\mathrm{mmHg}$ and diastolic arterial pressure $>90 \mathrm{mmHg}$ ) and marked proteinuria (>300mg/24hours) [2]. Other less frequent complications may also take place, such as acute kidney injury, thrombocytopenia, hemolysis, placental abruption, lung edema or acute liver damage, many of them are found in a more critical variant of preeclampsia, known as Hemolysis-Elevated Liver Enzymes-Low Platelet Count (HELLP) syndrome [3]. Several risk factors for the manifestation of preeclampsia have been compiled, and many of them are the same to those described for the most frequent cardiovascular pathologies: obesity, diabetes mellitus, renal diseases or chronic hypertension. It has also been observed that women who have suffered preeclampsia are more exposed to the risk of suffering cardiovascular illnesses in the future [4]. Endothelial dysfunction is known to be a common link between preeclampsia and these cardiovascular diseases. Besides, both cardiovascular diseases and preeclampsia share an inflammatory process associated with an infiltration of low density lipoproteins particles (LDLs) into the subendothelial artery wall in atherosclerosis of coronary vessels and in acute atherosis of spiral arteries in preeclampsia [5].

Despite the numerous studies carried out so far, an effective treatment for this illness has yet not been discovered, with labor and the consecutive delivery of the placenta being the only way of alleviating the symptoms. This fact emphasizes the key role that the placenta plays in this illness. During the development of the placenta, various angiogenic processes take place, including trophoblastic migration, followed by an invasion in the uterine vasculature, whose objective is establishing an uteroplacental circulation for nutrition and gas exchange between the mother and the fetus. The importance of the Transforming Growth Factor-beta (TGF-beta)/endoglin signaling pathway in this process, in which endoglin acts regulating the trophoblastic differentiation has been demonstrated [6]. In preeclampsia, an inadequate trophoblastic invasion leads to an inappropriate vascular remodeling, which generates conditions of hypoxia and increased oxidative stress in the placenta [7]. Even though the mechanism through which the illness is produced is unknown, it can be postulated that these hypoxic conditions may trigger various signaling pathways leading to a deregulation of the angiogenic factors needed for the placenta's normal vasculogenesis.

Preeclampsia is characterized by a rise in plasmatic levels of angiogenesis-related soluble factors like the soluble factor fms-like tyrosine kinase-1 (sFlt-1) and soluble endoglin (sEng) [8-10]. Flt-1 is a receptor for vascular endothelial growth factor (VEGF), whereas its soluble form sFlt-1 is able to sequester VEGF in the medium. In addition, sEng is able to bind TGF-beta family members, thus 
inhibiting the role of these ligands in angiogenesis. Elevated plasma levels of sFIt-1 and sEng have been reported in pregnant women several weeks before the appearance of preeclampsia, and both molecules play a fundamental role in its physiopathology, since their antiangiogenic characteristics make them clear effectors of the dysfunction happening in the maternal endothelium. sFlt-1 binds to VEGF and placenta growth factor-1 (PIGF), and blocks their angiogenic actions in vascular tissues by preventing their binding to their membrane receptors. In addition, several studies carried out in rat and mouse show that the rise of the plasmatic levels of sFlt-1 is capable of inducing hypertension, proteinuria and glomerular endotheliosis $[8,9,11]$. sEng may impair binding of TGF-beta1 to its receptor on the cell surface, thus leading to deregulation of TGF-1 signaling, specifically the activation of endothelial nitric oxide synthase and vasodilation induced by TGF-beta1 in the presence of endoglin [12-14]. The rise of sEng in plasma is correlated to the severity of preeclampsia and with the levels of sFlt-1, including the HELLP syndrome where the concentration of sEng is even higher than that of sFlt1. The levels of sEng rise at the end of the second trimester of pregnancy in women presenting hypertension, preeclampsia and in pregnancies where placenta detachment takes place $[15,16]$. These levels also rise in pregnancies associated with a restriction of the uterine growth (IUGR) [17]. The purpose of the present review is to analyze the possible role of endoglin in the genesis of preeclampsia.

\section{ENDOGLIN: AN AUXILIARY RECEPTOR OF THE TGF-BETA SYSTEM}

The family of proteins to which TGF-beta belongs to, consists of a series of cytokines, including TGFbeta isoforms, activins and bone morphogenetic proteins (BMPs). In mammals TGF-beta presents three isoforms TGF-beta1, TGF-beta2 and TGF-beta3 which regulate several cellular functions such as proliferation, differentiation and migration [18]. TGF-betas play a role in essential pathophysiological processes, both in the embrionary stage, where it is necessary for vasculogenesis, and in the adult life, where these ligands participate in maintaining vascular homeostasis and in other pathological conditions such as fibrosis or cancer $[19,20]$.

Members of the TGF-beta family share a common signaling pathway that is activated upon ligand binding to a heterodimeric complex consisting of two kinds of serine/treonine kinase receptors (type I and type II), known as activin receptor-like kinases (ALK). Initial ligand binding to each receptor type depends on their affinity for the cytokine. Thus, BMPs bind to the receptor type I [21], while TGF-beta and activin, like other members of the superfamily, bind first to the receptor type II $[22,23]$. In addition, the heterocomplex formed is also different in that BMPs do not need the cooperation of both receptors for signaling [21], while both TbetaRII as ActRIIA or ActRIIB (TGF-beta and activin type II receptors, respectively) need to recruit the type I receptor which can be ALK1 or ALK5 in TGF-beta signaling and ALK4 in the case of activins. This leads to the activation of type I receptor by the 
constitutively active type II receptor which phosphorylates type receptor in different residues, depending on the kind of type I receptor. Next, the phosphorylated type I receptor activates the canonical signaling cascade of Smad proteins (or another Smad-independent pathways), which are responsible for directing the signal to the nucleus where they participate in transcriptional regulation of target genes. This signaling cascade depends on the agonist and the type I and type II receptors involved [24].

In the case of TGF-beta, the signaling pathway is triggered when TGF-beta is bound to the type II receptor (TbetaRII), which then recruits and activates the type I receptor (ALK1 or ALK5 in endothelial cells) by phosphorylation of specific serine and threonine residues [25]. Next, the phosphorylated type I receptor activates the Smad signaling cascade. Thus, R-Smads or receptor-regulated Smads, are phosphorylated by the type I receptor via two different pathways, the Smad $1 / 5 / 8$, which is activated by ALK1 and the Smad 2/3 pathway triggered by ALK5. Once in the nucleus, Smad proteins promote different cellular responses [24].

In addition to the heterodimeric association between type I and type II receptors, the TGF-beta receptor complex also contains a third group of auxiliary receptors, named type III receptors that include betaglycan and endoglin, capable of binding several members of the TGF-beta superfamily.

\section{ENDOGLIN STRUCTURE AND FUNCTION}

Endoglin is a membrane glycoprotein predominantly expressed in endothelial cells [26], with an upregulated expression in zones with vascular damage [27], inflammation [28], active angiogenesis [29] and in tumor vessels [30]. Moreover, the presence of endoglin has also been observed in other cellular types such as macrophages [31], stromal cells [32], smooth muscle vascular cells [33], syncytiotrophoblasts of full term placenta [34] or certain hematopoietic cells [35]. The functional importance of endoglin in the vascular development during the embrionary stage is revealed by the fact that endoglin knockout mice die at mid-gestation because of defective angiogenesis [36-38]. The clinical importance of endoglin is illustrated by the observation that mutations in the endoglin gene result in the Rendu-Osler-Weber syndrome or Hereditary Hemorrhagic Telangiectasia type 1 (HHT1), an illness characterized by the presence of epistaxis, telangiectases and arteriovenous malformations in several organs, including lung, liver and brain $[39,40]$.

Human endoglin is a glycosylated type I integral membrane protein of $180-k D a$ formed by a disulfide-linked homodimer [41], capable of binding TGF-beta1 and TGF-beta 3 (but not TGF-beta2), activin-A, BMP-7, BMP-2 and BMP-9 [12]. Endoglin has three well defined regions: i) an extracellular region of 561 amino acids that consists of an orphan domain and a zona pellucida (ZP) domain; ii) a single hydrophobic transmembrane domain; and iii) a short cytosolic domain [42]. In primates, each 
endoglin subunit comprises one ZP domain in the juxtamembrane region $[43,44]$ that contains an ArgGly-Asp (RGD) peptide sequence [42] that is known as a cell recognition motif for integrins found in numerous adhesive proteins of the extracellular matrix (ECM). However, this sequence does not appear in rat or mice endoglin, suggesting that this is a recent adaptation. The NH2-terminal domain of endoglin does not show any significant homology to any other protein family/domain and thereby has been named "orphan" domain [44]. The importance of this region in ligand binding was elucidated since experiments with two deletional endoglin constructs showed that the orphan domain was enough to bind BMP-9 [45]. A scheme showing the major domains of endoglin structure is shown in Fig. 1.

The cytosolic domain of endoglin is constitutively phosphorylated, and can be targeted by serine and threonine kinases $[46,47]$, including the TGF-beta type I and II receptors $[48,49]$. It has been shown that the endoglin phosphorylation status can influence its subcellular localization [49] and cellular migration [50]. Endoglin cytoplasmic domain contains a consensus postsynaptic density 95/Drosophila disk large/zonula occludens-1 (PDZ)-binding motif present at the carboxyl terminus that mediates endoglin interaction with several PDZ domain-containing proteins and endoglin phosphorylation of distal threonine residues $[49,51]$ (Fig. 1).

\section{THE MEMBRANE ISOFORMS: L-ENDOGLIN AND S-ENDOGLIN}

Two membrane-bound isoforms of the protein have been described in humans and mice, the L-(large) endoglin (L-endoglin), which is the most abundant isoform, and the S-(short) endoglin (S-endoglin) which is generated by an alternative splicing of the same gene, due to retention of intron 14 (Fig. 1B). The difference between L-endoglin and S-endoglin resides in their cytoplasmic tail. Thus, S-endoglin is 33 amino acids shorter in humans and 12 amino acids shorter in mice than L-endoglin [52, 53]. Lendoglin and S-endoglin seem to have different functional properties, as the lethal phenotype of endoglin-null $\left(\mathrm{Eng}^{-/-}\right)$mice was not rescued by breeding transgenic mice over expressing S-endoglin into the endoglin-null background [53]. Alternative splicing factor or splicing factor-2 (ASF/SF2 or SRSF1) seems to play a role in the intron retention responsible for alternative splicing of the endoglin gene, as SRSF1 over expression increases the proportion of S-endoglin with respect to L-endoglin [54]. These two isoforms display differences in their phosphorylation status, but this fact does not alter the endoglin's capacity to bind TGF-beta [46, 52]. However, both isoforms show a different affinity for the TGF-beta type I receptors ALK1 and ALK5 $[55,56]$. Interestingly, the S/L ratio of both endoglin isoforms was increased during senescence of human endothelial cells in vitro, as well as during aging of mice in vascularized tissues [56].

\section{Regulation of Vascular Function by Membrane Endoglin Isoforms}


Because L-endoglin is the most abundant and first discovered endoglin isoform, most of the studies carried out until now have been focused on the physiological function in this isoform. L-endoglin seems to play a major role in regulating vascular tone [12]. Studies in mice haploinsufficient for endoglin $\left(\mathrm{Eng}^{+/}\right)$showed a lower vascular response to nitric oxide dependent vasodilators such as acetylcholine or bradykinin than wild type littermates $\left(E n g^{+/+}\right)$. This deficient response was the consequence of an impaired endothelium-dependent vasodilatation, produced by a smaller production of nitric oxide (NO) due to a decrease of the endothelial nitric oxide synthase (eNOS) expression and activity in these mice [14]. On the other hand, Toporsian et al. [13], showed that endoglin haploinsufficiency produces an uncoupling of eNOS and heat shock protein 90 (Hsp90) in endothelial cells leading to increased production of $\mathrm{O}^{2-}$ and decreased levels of NO, suggesting that endoglin also acts stabilizing eNOS in the caveolae. With respect to the role of S-endoglin in vascular tone, we have reported that transgenic mice overexpressing the short endoglin isoform (S-Eng $\left.{ }^{+}\right)$ develop hypertension because of an alteration in the TGF-beta1-induced synthesis of NO [56]. Accordingly, opposing functional effects of L-endoglin and S-endoglin isoforms on the NO synthesis and vasodilatation regulation have been postulated [12].

A crucial role of endoglin in angiogenesis is demonstrated by the fact that endoglin $\mathrm{KO}\left(\mathrm{Eng}^{-/}\right)$mice die during the fetal life due to impaired neoangiogenesis [36-38]. TGF-beta1 is a well-known regulator of angiogenesis. Depending on the specific microenvironment, TGF-beta1 can be angiogenic, favoring the formation of new vessels, or anti-angiogenic favoring vessel stabilization $[19,51]$. The ability of endoglin to regulate the TGF-beta1-dependent angiogenic response was noted by Li et al. in primary cultures of human endothelial cells, in which they suppressed endoglin expression using an antisense approach. The result obtained was not only a reduced formation of capillary tubes, but also a higher mortality in endoglin deficient endothelial cells [57]. These data suggest that endoglin promotes angiogenesis by antagonizing TGF-beta1 inhibitory effects in endothelial cells.

Several studies have also revealed that $\mathrm{Eng}^{+/}$mice show a deficient adult angiogenesis, as demonstrated by a lesser formation of blood vessels after ischemia [58] and during the growth of solid tumors [59]. The molecular mechanism by which endoglin regulates angiogenesis has been proposed by Lebrin et al. [60]. In this model, endoglin favors ALK1 signaling pathway promoting proliferation and migration in endothelial cells. Thus, in the absence of endoglin, TGF-beta1 signaling occurs through ALK5, maintaining a quiescent endothelium [60]. Supporting this view, experiments carried out with cell transfectants expressing L-endoglin or S-endoglin revealed that both L-endoglin and S-endoglin are able to decrease the inhibitory effect of TGF-beta1 and promote cell proliferation. However, whereas L-endoglin abolishes this effect completely, S-endoglin only attenuates it partially [61]. 
While most of the endoglin results on angiogenesis described above can be attributed to the predominant L-endoglin isoform, some reports have addressed the role of S-endoglin in this process. Thus, studies in S-Eng+ mice reveal that these animals show an impaired angiogenesis [53]. S-endoglin is able to interact with both TGF-beta type I receptors, ALK5 and ALK1, although the interaction with ALK5 was stronger than with ALK1 [56]. Moreover, experiments performed by Velasco et al. [62] in myoblasts transfected with L- or S-endoglin show that L-endoglin decreases collagen and CTGF expression induced by TGF-beta1 while a high increase in both proteins is shown by S-endoglin transfectants. Thus, it can be suggested that, while L-endoglin favors the TGF-beta/ALK1/Smad1/5/8 pathway, promoting proliferation and endothelial migration, S-endoglin, which presents a lesser interaction with ALK1, favors signaling via the TGF-beta/ALK5/Smad2/3 pathway, promoting the synthesis of extracellular matrix and hindering the proliferation and endothelial migration $[60,62,63]$ (Fig. 2).

Taken together, these experiments suggest that in contrast to the proangiogenic and vasodilator effects of the predominant L-endoglin isoform, S-endoglin has antiangiogenic and vasoconstrictor effects. Although, there is not any study on the role of S-endoglin in preeclampsia, this could be an important protein to be explored in this disease.

\section{SOLUBLE ENDOGLIN}

Besides the membrane-bound isoforms described above, a soluble form of endoglin has been described in plasma, serum and urine of patients with different pathologies such as preeclampsia [10], atherosclerosis [57], and a wide variety of cancer types [29, 30, 51, 64]. Furthermore, high levels of sEng in plasma from patients who have suffered a myocardial infarction correlate with a poor prognosis [65]. High levels of sEng in plasma are also associated with the presence of vascular alterations in patients with diabetes or hypertension [66]. Soluble endoglin is the result of a proteolytic cleavage of the membrane isoforms. Several experimental evidences suggest that the membrane metalloprotease (MMP) MT1-MMP or MMP-14 has a key role by cleaving the Gly-Leu bond at the juxtamembrane position 586 of endoglin, and releasing the extracellular domain to the plasma [67]. However, the role of other MMPs in the shedding of endoglin cannot be discarded.

In plasma, sEng can bind several ligands, among them TGF-beta1, BMP-9 and BMP-10 through the orphan domain, and with a higher affinity than the full length membrane isoform $[10,45,68]$. When sEng binds circulating TGF-beta1, the availability of the cytokine to interact with its membrane receptors decreases, as SEng is unable to interact directly with the extracellular region of TGF-beta receptors type I and type II [69] (Fig. 2). This way, an imbalance in the natural signaling pathway of TGF-beta1 would occur, inhibiting eNOS activation, decreasing the NO production and hindering vasodilatation and angiogenesis. This hypothesis is supported by experiments performed by 
Venkatesha et al. [10] showing that increased levels of sEng reduce TGF-beta1 binding to its membrane receptors in endothelial cells. As a result, sEng prevents the activation of Smad2/3 via TGFbeta1, impairing its signaling. In addition, sEng abolishes eNOS activation via TGF-beta1 which leads to the eNOS dependent vasodilation inhibition in rat renal and mesenteric cells treated with similar sEng concentrations to those seen in preeclamptic women.

It has been reported that the extracellular domain of endoglin present in either mouse or human sEng, is able to inhibit angiogenesis in in vivo angiogenesis assays. Therefore, sEng inhibited sprouting blood vessel formation induced by VEGF in a chick chorioallantoic membrane (CAM) assay and in VEGF/FGFinduced angiogenesis using in vivo angioreactors [68]. These data agree with previously published observations that sEng inhibits formation of capillary tubes in vitro [10] and reduces spontaneous and VEGF-induced endothelial sprouting in cultured HUVEC cells [67]. The anti-angiogenic activity of sEng was also confirmed by its ability to reduce the growth of tumors induced by subcutaneous implantation of colon-26 adenocarcinoma cells in mice [68].

Membrane endoglin-enhanced angiogenesis has been related with its ability to activate the ALK1-dependent pathway $[45,69,70]$. Recent studies have established BMP-9 and BMP-10 as major ligands in the angiogenic pathway of ALK1. The extracellular domain of mouse and human endoglin was able to bind directly, specifically, and with high affinity to BMP-9 and BMP-10, suggesting that the anti-angiogenic effect of sEng may be attributed to inhibition of the signaling triggered by BMP-9 and BMP-10, rather than by TGF-beta1 or TGF-beta3.

\section{REGULATION OF ENDOGLIN EXPRESSION}

The human endoglin gene maps to chromosome 9q34qter [71]. Similarly to other components of the TGF-beta signaling pathway, the endoglin promoter is a TATA- and CAAT-less promoter with GC-rich sequences near to the transcription initiation site $[72,73]$ and Sp1 motifs that are necessary for basal transcription [74]. The endoglin promoter also contains consensus sequences for several transcription factors, including Smad, HIF-1, KLF6, NFkB, GATA-2, AP2, glucocorticoids, vitamin D and Ets [27, 7275].

It has been shown that endoglin promoter presents a stronger activity in endothelial cells as compared with other cell types $[72,73]$. The genetic expression of endoglin can be upregulated by several components of the TGF-beta signaling pathway, including TGF-beta1, BMP-9 and the constitutively activated ALK1 [61, 73, 76-78]. This upregulated expression appears to be mediated by a synergistic cooperation between Sp1 and Smad transcription factors [74].

Hypoxia is one of the best studied inductors of endoglin expression [79]. Under hypoxic conditions, the hypoxia-inducible factor 1 alpha (HIF-1alpha), subunit of HIF-1 heterodimer, plays a critical role [80]. 
When $\mathrm{pO}_{2}$ decreases, cytoplasmic HIF-1alpha translocates to the nucleus and dimerizes with HIF1beta. The HIF-1 heterodimer binds the hypoxia response element (HRE) region present in the endoglin promoter in cooperation with $\mathrm{Sp} 1$ and the coactivator $\mathrm{CBP} / \mathrm{P} 300$, thus stimulating the expression of endoglin mRNA and the subsequent protein synthesis. This stimulatory effect is further enhanced when the HIF-1alpha/Sp1 complex collaborates with the TGF-beta/Smad3 signaling pathway [79].

Endoglin transcription can be upregulated by agonists of Liver X receptors (LXRs) [81]. LXRs are ligandactivated transcription factors that form heterodimers with the retinoic $X$ receptor (RXR), regulating the expression of different target genes [82]. These receptors are found in several tissues such as liver, spleen, kidney and placenta, where they carry out important functions. Two variants of LXR, alpha and beta have been described. Whereas LXR-alpha is highly expressed mainly in the liver, kidney, small intestine, adipose tissue and macrophages, the presence of LXR-beta is ubiquitous in most tissues, although its expression level is quite low [83]. Henry-Berger et al. [81] have demonstrated that LXRalpha/RXR heterodimer is capable of binding at least one among six putative LXR response elements (LXRE) of the endoglin promoter, activating its expression in response to 22(R)-hydroxy cholesterol, T0901317 (a synthetic and selective agonist, specific for LXRalpha and LXRbeta) or synthetic RXR agonists.

A transcriptional activation of endoglin upon endothelial injury has been described in cultured endothelial cells and in animal models. This response to vascular injury involves the cooperative interaction between Sp1 and Kruppel-like factor 6 (KLF6) in the endoglin promoter [27]. Several members of Ets family of transcription factors, including Erg, Elf-1 and Fli-1 and Ets-2 have also been reported as regulators of endoglin expression in the endothelium $[73,75]$.

\section{ENDOGLIN AND PREECLAMPSIA}

Both total endoglin expression and sEng plasma levels have been reported to be increased in preeclampsia [10]. In addition, a pathogenic role for sEng has been postulated. Here, the possible mechanisms involved in endoglin overexpression in preeclampsia have been reviewed.

\section{HYPOXIC ENVIRONMENT AND ENDOGLIN EXPRESSION IN PREECLAMPSIA}

Various studies have demonstrated that certain pathologies such as preeclampsia or cancer develop with some degree of cellular hypoxia, which could be related with the increased membrane endoglin or the levels of its soluble form $[50,64,79]$.

Studies in placentas from preeclamptic women have shown an increase in the levels of endoglin, HIF1alpha and TGF-beta3 compared with placentas from normal pregnancies [17]. Both HIF-1alpha and TGF-beta3 appear during the first trimester of pregnancy, in response to low oxygen levels, and may 
promote the subsequent increased expression of endoglin. It is also known that HIF-1alpha not only binds to the endoglin promoter, but also interacts with the HRE region in the TGF-beta3 gene, activating its expression (Fig. 3). Studies carried out in rats with reduced uterine perfusion with silver clips placed on the aorta and on ovarian's arteries, show an increase in HIF-1alpha and soluble endoglin release, which suggests that hypoxia does not only provoke a rise of the membrane endoglin, but it also favors the release of soluble protein to the plasma [84].

LXR-alpha and LXR-beta are expressed in human and mouse trophoblasts and the placenta from early gestation. Its function in the placenta seems to be related with the control of the fatty acids metabolism and cholesterol between mother and fetus, showing a primordial function in pregnancy. In the human placenta LXRalpha and LXRbeta expressions increases during normal pregnancy. This is paralleled by the expression of their prototypical target genes, e.g., the cholesterol transporter $A B C A 1$. Interestingly, early-onset preeclamptic placenta reveals a significant upregulation of ABCA1 [85]. A further link of LXRs with preeclampsia derives from the reported association between the LXRbeta gene polymorphism and preeclampsia [86]. In pregnancies complicated by preeclampsia, expression of LXRalpha, LXRbeta and fatty acid transporter CD36, was significantly decreased in placental tissues and the placental LXRbeta protein levels were also reduced, suggesting a possible role for this receptor, as a transcriptional regulator, in preeclampsia [87].

In relation with placental hypoxia, culture of JAR trophoblast cells and human first trimester placental explants under low oxygen concentration lead to increased expression of LXRalpha and ABCA1 which was further enhanced by the LXR agonist T0901317. Deregulation of this system in early preeclampsia might be the result of placental hypoxia with important consequences for maternal-fetal cholesterol transport. A crosstalk between hypoxia and oxidative stress has been described by several authors. Under hypoxic conditions, reactive oxygen species (ROS) are produced by a flavoprotein-containing $\mathrm{NAD}(\mathrm{P}) \mathrm{H}$ or by mitochondria as a mechanism that contributes to stabilize HIF-1alpha and consequently mediates the transcriptional response to hypoxia [88]. Thus, hypoxic conditions may favor the generation of ROS in preeclampsia. Indeed, oxidative stress has been shown to play a pivotal role in the etiopathogenesis of preeclampsia [89]. This oxidative stress is defined by an imbalance between pro-oxidant and antioxidant factors, which is characterized by an increase in serum and placenta tissue of ROS molecules, hydrogen peroxide [90] and peroxynitrite, as well as the decrease of the enzymatic expression of the superoxide dismutase (SOD) or the nitric oxide synthase [91]. In trophoblasts of preeclamptic placentas, the lack of endogenous protective factors such as the antioxidant heme oxygenase-1 (HO-1), superoxide dismutase and glutathione peroxidase may contribute to the increased production of soluble factors such as sEng and sFlt-1, a splice variant of VEGF receptor 1 [92-94]. Supporting this view, Tam Tam et al. have recently demonstrated that there 
is a dependent relation between oxidative stress and vascular effects of sFlt-1, since the administration of tempol prevented the hypertensive effect induced by the long term administration of sFlt-1 in pregnant rats [95].

ROS can interact and modify critical macromolecules existing in the cell such as lipids, proteins or even cause damages in cellular DNA. Several studies have demonstrated high levels of LDL in the serum from women with preeclampsia and these LDL show a higher susceptibility to oxidation giving oxidized LDL (oxLDL) [96, 97]. In vitro studies have demonstrated the ability of oxLDL to inhibit trophoblastic migration through an LXR-dependent mechanism [98]. Endogenously oxygenated cholesterol derivatives such as 24(S)-hydroxycholesterol or 22(R)-hydroxycholesterol (oxysterols), were also identified as endogenous agonists of LXRs. Oxysterols are detected at relatively high levels in the placenta and it has been suggested a role of LXRs in the reproductive system and a potential application of LXR agonists in the treatment of reproductive pathologies [99]. In vitro studies have demonstrated the ability of oxLDL to inhibit differentiation and fusion of term primary trophoblasts and trophoblastic migration by activating LXRs [98]. Of note, activation of LXR can induce the expression of endoglin [81].

\section{MECHANISM OF SOLUBLE ENDOGLIN RELEASE IN PREECLAMPSIA}

The exact molecular mechanisms underlying the release of soluble endoglin in preeclampsia remain to be elucidated. Studies carried out in rat models where an ischemia of the placenta (reduced uteroplacental perfusion, RUPP) had been produced, show an increase in HIF-1alpha and membrane and soluble endoglin, suggesting that hypoxia not only provokes a rise of membrane bound endoglin, but also favors the release of protein to the plasma [84]. Besides, Redman and Sargent [100] have described that ROS generated by oxidative stress in the placenta, can produce an inflammatory process that might contribute to the release of sFlt-1 and sEng, via NFkB-activation. Moreover, they have described that hypoxia is not a limiting factor for the release of these molecules in the cell [101]. This hypothesis is supported by the fact that placental villous explants release significant amounts of sEng into the culture medium in non-hypoxic conditions, after the treatment with TNF-alpha [92]. Recently, increased levels of protein S100B, a calcium-binding protein, has been described in placentas from patients with preeclampsia. Further, in vitro studies have demonstrated that S100B, induced through oxidative stress, is capable of regulating the release of $s$ Eng in endothelial cells [102].

The metalloprotease MT1-MMP (MMP-14) is able to shed endoglin from the plasma membrane of endothelial cells [67]. Interestingly, MMP-14 is expressed in placental in syncityotrophoblasts, where it is able to release sEng from membrane endoglin [103]. Furthermore, it has been described that hypoxia is able to regulate the expression and activity of some metalloproteases. In the case of MMP14, the main protease implicated in endoglin shedding until now, an adaptive post-translational 
response to hypoxia was observed [104]. Thereby, hypoxia produces an accumulation and activation of MMP-14 in the plasma membrane. Another possible mechanism relating hypoxia, oxidative stress and sEng release is the increased levels of oxysterols detected in the placenta and their possible involvement in reproductive pathologies [99]. It has been recently described that LXR activation by oxysterols in cultured trophoblasts increases MMP-14 expression and activity and enhances the release of sEng. Furthermore, oxysterols administration to mice increases the plasma concentrations of sEng [105]. In turn, the capability of MMP-14 to activate HIF-1alpha was described in hematopoiesis [106], thus suggesting a bidirectional effect between hypoxia and MMP-14.

$\mathrm{Gu}$ et al. [107] have described that cultured placental trophoblasts from preeclamptic women produced significantly more sEng, sFlt-1, and PIGF than normal trophoblasts when cells were incubated under normoxic conditions $\left(20 \% \mathrm{O}_{2}\right)$. In addition, when placental trophoblasts were cultured under low oxygen concentrations $\left(2 \% \mathrm{O}_{2}\right)$, sEng and sFlt-1 productions increased in preeclamptic trophoblasts, but not in normal trophoblasts. Moreover, experiments performed by Aoki et al. [108] showed that human choriocarcinoma cells treated with serum from preeclamptic women in normal conditions produced higher levels of SEng and decreased HO-1 levels with respect to untreated cells. It is important to note that these experiments were performed using preeclamptic serum samples and since both trophoblasts and sera were previously exposed to hypoxia, the presence of hypoxia-induced products in these samples cannot be excluded. Taken together, these data suggest that, in addition to hypoxia stimuli, preeclampsia serum contains some components that might contribute to the release of soluble endoglin. The regulatory effect of HO-1, an enzyme that catalyzes oxidation of the hemo group and favors the synthesis of antioxidants, has been described, as HO-1 inhibits the secretion of sEng and sFlt-1 from human villous explants [109]. Moreover, the treatment with cobalt protoporphyrin, a HO-1 inductor, diminishes hypertension and other characteristics common to preeclampsia, using a reduction in RUPP rat model [110], demonstrating a cytoprotective effect of $\mathrm{HO}-1$ and pointing to a possible therapeutical pathway. Relating to the protective effect of HO-1, Cudmore et al. [111] have recently described the interdependence between HO-1 and phosphoinositide 3-kinase/Akt (PI3K/Akt) signaling pathway. The PI3K/Akt route is activated in the presence of various factors such as insulin, VEGF and angiopoietin with a resulting protective effect in the cell. Knockout mice for HO-1 reveal a lower expression of $\mathrm{p}-\mathrm{Akt}$, and so do placentas from patients with preeclampsia. Furthermore, the loss of PI3K/Akt and/or HO-1 activity promotes sEng release, indicating that both are necessary to maintain the balance between the soluble form and the membrane protein. Several authors have described the increase in preeclampsia of the protein for growth arrest and DNA damage inducible 45 alpha (Gadd45). This protein acts as a response to stress conditions in the cells, activating another MAPK stress-induced response protein, p38, whose expression is also high in preeclampsia. When activated p38 induces the release of sFlt-1 and sEng, 
whose plasmatic levels are correlated with the increase in the Gadd45 and p38 levels [112, 113]. Moreover, inhibition of Gadd45alpha or p38 reestablishes the normal levels of sFlt-1 and sEng in endothelial cells and diminishes the oxidative stress produced by hypoxia, thus promoting angiogenesis [112].

In addition to hypoxia and oxidative stress, other mechanisms can be involved in increased sEng release from the placenta in preeclampsia. In this sense, Zhou et al. [109] have demonstrated the relationship between the rise of soluble endoglin and the presence of agonist antibodies to angiotensin receptor type I (AT1-AA). AT1-AA is found in the serum of patients with preeclampsia and seems to induce the expression of TNF-alpha via AT1R, which, in turn, induces ET1 and stimulates the production of sEng. Accordingly, the rise in the levels of TNF-alpha, a proinflammatory cytokine, in preeclampsia has been described [114]. In a rat model of preeclampsia (RUPP), increased levels of AT1-AA, ET-1 and sEng have been observed. Interestingly, the administration of AT1-AA to nonpregnant rats induced an increase in arterial pressure and in plasma levels of sFlt-1, sEng and ET-1. By contrast, suppression of circulating AT1-AA by B-cell depletion in RUPP rats was associated with lower blood pressure and decreased ET-1 plasma levels [115]. It should be noted that ET-1 has also been suggested to contribute to hypertension and the induction of oxidative stress and endoplasmic reticulum stress in preeclampsia, while these two types of stress have been proposed to induce many of the clinical manifestations of this disorder [116].

Taking into account the data described above, it can be postulated that cells from normal placentas might be able to compensate, or be more resistant, to low oxygen tension than cells from preeclamptic placentas. In addition, the release of sEng does not seem to be due to the activation of a single signaling pathway. Instead, it is a consequence of various stimuli, which end up in the shedding of the extracellular region from the full-length protein to the plasma compartment, thus allowing sEng to exert an antiangiogenic effect by inhibiting the TGF-beta and/or the BMP-9 and BMP-10 signaling pathway. A schematic overview of the main mechanisms involved in soluble endoglin release in preeclampsia is given in Fig. 4.

\section{PERSPECTIVES AND POSSIBLE TREATMENT STRATEGIES}

Preeclampsia is an illness which takes place with hypertension and proteinuria and can lead to very serious complications during pregnancy. The absence of symptoms in the first months of gestation and the lack of an adequate treatment worsen this situation even more. Actually, the only treatment for preeclampsia is delivery of the fetus and placenta after which, a full recovery of the patient is usually achieved. Currently, there is a high demand for therapeutic strategies that could extend the pregnancy in these patients for only a few weeks of gestation to reduce maternal and neonatal morbidity and mortality. According to the pathogenic mechanisms discussed above, it can be speculated that the 
different therapies to treat preeclampsia should be directed to restoring the normal angiogenesis balance in the maternal circulation. This goal may be approached by: i) inhibiting the release of soluble factors sFlt-1 and sEng; ii) inhibiting sFlt-1 and sEng action through specific monoclonal antibodies or any other specific inhibitor; or iii) using agents that enhance endogenous VEGF, PIGF or TGF-beta production.

While the regulatory mechanisms underlying the alternative splicing machinery that result in the synthesis of sFIt-1 remain to be elucidated, the release of sEng has recently begun to be characterized. More specifically, several authors have identified MMP-14 as the molecule responsible for endoglin shedding in preeclampsia and other conditions $[67,103,105]$. Thus, it can be hypothesized that blockade of the enzymatic activity of this metalloprotease by substrate competition or by any other mechanism could prevent endoglin shedding with potential therapeutic implications. Current research on MMP-14 inhibition is a hot topic, as MMPs have been shown to be key players in both extracellular matrix remodeling and cell migration during cancer metastasis and other prevalent pathologies. Blockade of metalloproteases is a difficult area of investigation due to the low specificity of most blocking substances, and the opposite functional effects of several related MMPs [117]. However, recent studies are providing valuable insights with potential application in this area. Thus, activation of MMP-2 by MMP-14 has been shown to be inhibited by the calcium-binding proteoglycans Testican-1, Testican-3 and Testican-3 splice variants $[118,119]$. Tissue inhibitors of metalloproteases 1 and 2 (TIMP-1 and TIMP-2) are naturally occurring inhibitors of MMP-14. A highly selective fully human MMP-14 inhibitory peptide (DX-2400) has been recently described [120]. Furthermore, synthetic peptides, mimicking the essential outermost strand motifs within the hemopexin domain of MMP-14 inhibit MMP-14 activity but without effect on the function of other MMPs, have been developed, and these peptides interfere with cancer metastasis without affecting primary tumor growth [108]. Thus, targeting MMP-14 could be a promising therapeutic approach to decrease endoglin shedding and, likely, the clinical symptoms observed in preeclampsia. In this regard, administration of an endoglin peptide containing the consensus MMP-14 cleavage site Gly-Leu prevented the oxysterol-dependent increase in arterial pressure and SEng plasma levels in mice [105], thus suggesting a potential usefulness of this peptide as an anti-hypertensive therapy in preeclampsia.

Studies on animal models that reproduce at least partially the characteristics of human preeclampsia should be a useful tool for testing novel therapeutic compounds. For example, treatment with VEGF121 (an isoform of VEGF) has shown to ameliorate preeclampsia signs and symptoms in a rat model that overexpresses sFlt-1 [121]. Recently, Kumasawa et al. [122] have generated a transgenic mouse model which overexpresses sFlt-1 specifically in the placenta. These mice show some features that resemble those observed in preeclampsia, such as impaired placental vasculogenesis, fetal growth 
restriction and hypertension. Treatment with pravastatin, a drug of the family of statins, used to inhibit the synthesis of cholesterol, induces placental and non-placental PIGF that counteracts sFlt-1 effect and improves some of the symptoms of preeclampsia [122]. Another statin, simvastatin decreases not only sFlt-1, but also sEng release through upregulating HO-1 in endothelial cells [92]. In addition, statins may act regulating the angiogenic balance and stimulating protective factors in preeclampsia as HO-1 [92]. These results suggest that statins may be useful for the treatment of altered angiogenesis in preeclampsia.

\section{ACKNOWLEDGEMENTS}

Studies from the authors' laboratories have been supported by grants from Ministerio de Ciencia e Innovación of Spain (SAF2010-19222 to CB; and SAF2010-15881 to JML-N), Genoma España (MEICA, to CB), Junta de Castilla y Leon (Grant GR100 to JML-N), Centro de Investigación Biomédica en Red de Enfermedades Raras (CIBERER, to CB) and Red de Investigación Cooperativa en Enfermedades Renales (REDINREN RD012/0021, to JML-N). CIBERER and REDINREN are initiatives of the Instituto de Salud Carlos III (ISCIII) of Spain supported by FEDER funds. BO is supported by a fellowship from Ministry of Science and Innovation (BES-2008-005550). 


\section{REFERENCES}

[1] Powe CE, Levine RJ, Karumanchi SA. Preeclampsia, a disease of the maternal endothelium: the role of antiangiogenic factors and implications for later cardiovascular disease. Circulation 2011; 123: 2856-2869.

[2] Maynard SE, Karumanchi SA. Angiogenic factors and preeclampsia. Semin Nephrol 2011; 31: 33-46.

[3] Wang A, Rana S, Karumanchi SA. Preeclampsia: the role of angiogenic factors in its pathogenesis. Physiology (Bethesda) 2009; 24: 147-158.

[4] Steinberg G, Khankin EV, Karumanchi SA. Angiogenic factors and preeclampsia. Thromb Res 2009; 123 Suppl 2: S93-99.

[5] Staff AC, Dechend R, Pijnenborg R. Learning from the placenta: acute atherosis and vascular remodeling in preeclampsia-novel aspects for atherosclerosis and future cardiovascular health. Hypertension 2010; 56: 1026-1034.

[6] Caniggia I, Taylor CV, Ritchie JW, et al. Endoglin regulates trophoblast differentiation along the invasive pathway in human placental villous explants. Endocrinology 1997; 138: 4977-4988.

[7] Kanasaki K, Kalluri R. The biology of preeclampsia. Kidney Int 2009; 76: 831-837.

[8] Maynard SE, Min JY, Merchan J, et al. Excess placental soluble fms-like tyrosine kinase 1 (sFlt1) may contribute to endothelial dysfunction, hypertension, and proteinuria in preeclampsia. J Clin Invest 2003; 111: 649-658.

[9] Levine RJ, Maynard SE, Qian C, et al. Circulating angiogenic factors and the risk of preeclampsia. N Engl J Med 2004; 350: 672-683.

[10] Venkatesha S, Toporsian M, Lam C, Hanai J, Mammoto T, et al. Soluble endoglin contributes to the pathogenesis of preeclampsia. Nat Med 2006; 12: 642-649.

[11] Gilbert JS, Babcock SA, Granger JP. Hypertension produced by reduced uterine perfusion in pregnant rats is associated with increased soluble fms-like tyrosine kinase-1 expression. Hypertension 2007; 50: 1142-1147.

[12] Lopez-Novoa JM, Bernabeu C. The physiological role of endoglin in the cardiovascular system. Am J Physiol Heart Circ Physiol 2010; 299: H959-974.

[13] Toporsian M, Gros R, Kabir MG, et al. A role for endoglin in coupling eNOS activity and regulating vascular tone revealed in hereditary hemorrhagic telangiectasia. Circ Res 2005; 96: 684-692.

[14] Jerkic M, Rivas-Elena JV, Prieto $M$, et al. Endoglin regulates nitric oxide-dependent vasodilatation. FASEB J 2004; 18: 609-611.

[15] Jeyabalan A, McGonigal S, Gilmour C, et al. Circulating and placental endoglin concentrations in pregnancies complicated by intrauterine growth restriction and preeclampsia. Placenta 2008; 29: 555563.

[16] Signore C, Mills JL, Qian C, et al. Circulating soluble endoglin and placental abruption. Prenat Diagn 2008; 28: 852-858.

[17] Yinon $Y$, Nevo O, Xu J, et al. Severe intrauterine growth restriction pregnancies have increased placental endoglin levels: hypoxic regulation via transforming growth factor-beta 3. Am J Pathol 2008; 172: 77-85. 
[18] Massague J. How cells read TGF-beta signals. Nat Rev Mol Cell Biol 2000; 1: 169-178.

[19] ten Dijke P, Arthur HM. Extracellular control of TGFbeta signalling in vascular development and disease. Nat Rev Mol Cell 2007; Biol 8: 857-869.

[20] Blobe GC, Schiemann WP, Lodish HF. Role of transforming growth factor beta in human disease. N Engl J Med 2000; 342: 1350-1358.

[21] Xia Y, Schneyer AL. The biology of activin: recent advances in structure, regulation and function. J Endocrinol 2009; 202: 1-12.

[22] Bragdon B, Moseychuk O, Saldanha S, et al. Bone morphogenetic proteins: a critical review. Cell Signal. 2011;23:609-620.

[23] Santibanez JF, Quintanilla M, Bernabeu C. TGF-beta/TGF-beta receptor system and its role in physiological and pathological conditions. Clin Sci (Lond) 2011; 121: 233-251.

[24] Massague J, Gomis RR. The logic of TGFbeta signaling. FEBS Lett 2006; 580: 2811-2820.

[25] Attisano L, Wrana JL, Lopez-Casillas F, et al. TGF-beta receptors and actions. Biochim Biophys Acta 1994; 1222: 71-80.

[26] Bourdeau A, Faughnan ME, Letarte M. Endoglin-deficient mice, a unique model to study hereditary hemorrhagic telangiectasia. Trends Cardiovasc Med 2000; 10: 279-285.

[27] Botella LM, Sanchez-Elsner T, Sanz-Rodriguez F, et al. Transcriptional activation of endoglin and transforming growth factor-beta signaling components by cooperative interaction between Sp1 and KLF6: their potential role in the response to vascular injury. Blood 2000; 100: 4001-4010.

[28] Torsney E, Charlton R, Parums D, et al. Inducible expression of human endoglin during inflammation and wound healing in vivo. Inflamm Res 2002; 51: 464-470.

[29] Duff SE, Li C, Garland JM, et al. CD105 is important for angiogenesis: evidence and potential applications. FASEB J 2003; 17: 984-992.

[30] Burrows FJ, Derbyshire EJ, Tazzari PL, et al. Up-regulation of endoglin on vascular endothelial cells in human solid tumors: implications for diagnosis and therapy. Clin Cancer Res 1995; 1: 1623-1634.

[31] Lastres P, Bellon T, Cabanas C, et al. Regulated expression on human macrophages of endoglin, an Arg-Gly-Asp-containing surface antigen. Eur J Immunol 1992; 22: 393-397.

[32] Robledo MM, Ursa MA, Sanchez-Madrid F, et al. Associations between TGF-beta1 receptors in human bone marrow stromal cells. Br J Haematol 1998; 102: 804-811.

[33] Conley BA, Smith JD, Guerrero-Esteo M, et al. Endoglin, a TGF-beta receptor-associated protein, is expressed by smooth muscle cells in human atherosclerotic plaques. Atherosclerosis 2000; 153: 323335.

[34] St-Jacques S, Forte M, Lye SJ, et al. Localization of endoglin, a transforming growth factor-beta binding protein, and of CD44 and integrins in placenta during the first trimester of pregnancy. Biol Reprod 1994; 51: 405-413.

[35] Rokhlin OW, Cohen MB, Kubagawa $\mathrm{H}$, et al. Differential expression of endoglin on fetal and adult hematopoietic cells in human bone marrow. J Immunol 1995; 154: 4456-4465. 
[36] Li DY, Sorensen LK, Brooke BS, et al. Defective angiogenesis in mice lacking endoglin. Science 1999; 284: 1534-1537.

[37] Bourdeau A, Dumont DJ, Letarte M. A murine model of hereditary hemorrhagic telangiectasia. J Clin Invest 1999; 104: 1343-1351.

[38] Arthur HM, Ure J, Smith AJ, et al. Endoglin, an ancillary TGFbeta receptor, is required for extraembryonic angiogenesis and plays a key role in heart development. Dev Biol 2000; 217: 42-53.

[39] Abdalla SA, Letarte M. Hereditary haemorrhagic telangiectasia: current views on genetics and mechanisms of disease. J Med Genet 2006; 43: 97-110.

[40] McAllister KA, Grogg KM, Johnson DW, et al. Endoglin, a TGF-beta binding protein of endothelial cells, is the gene for hereditary haemorrhagic telangiectasia type 1. Nat Genet 1994; 8: 345-351.

[41] Gougos A, Letarte M. Biochemical characterization of the 44G4 antigen from the HOON pre-B leukemic cell line. J Immunol 1988; 141: 1934-1940.

[42] Gougos A, Letarte M. Primary structure of endoglin, an RGD-containing glycoprotein of human endothelial cells. J Biol Chem 1990; 265: 8361-8364.

[43] Jovine L, Darie CC, Litscher ES, et al. Zona pellucida domain proteins. Annu Rev Biochem 2005; 74: 83-114.

[44] Llorca O, Trujillo A, Blanco FJ, et al. Structural model of human endoglin, a transmembrane receptor responsible for hereditary hemorrhagic telangiectasia. J Mol Biol 2007; 365: 694-705.

[45] Alt A, Miguel-Romero L, Donderis J, et al. Structural and functional insights into endoglin ligand recognition and binding. PLoS One 2012; 7: e29948.

[46] Lastres P, Martin-Perez J, Langa C, et al. Phosphorylation of the human-transforming-growthfactor-beta-binding protein endoglin. Biochem J 1994; 301 ( Pt 3): 765-768.

[47] Yamashita H, Ichijo H, Grimsby S, et al. Endoglin forms a heteromeric complex with the signaling receptors for transforming growth factor-beta. J Biol Chem 1994; 269: 1995-2001.

[48] Guerrero-Esteo M, Sanchez-Elsner T, Letamendia A, et al. Extracellular and cytoplasmic domains of endoglin interact with the transforming growth factor-beta receptors I and II. J Biol Chem 2002; 277: 29197-29209.

[49] Koleva RI, Conley BA, Romero D, et al. Endoglin structure and function: Determinants of endoglin phosphorylation by transforming growth factor-beta receptors. J Biol Chem 2006; 281: 25110-25123.

[50] Romero D, O'Neill C, Terzic A, et al. Endoglin regulates cancer-stromal cell interactions in prostate tumors. Cancer Res 2011; 71: 3482-3493.

[51] Bernabeu C, Lopez-Novoa JM, Quintanilla M. The emerging role of TGF-beta superfamily coreceptors in cancer. Biochim Biophys Acta 2009; 1792: 954-973.

[52] Bellon T, Corbi A, Lastres P, et al. Identification and expression of two forms of the human transforming growth factor-beta-binding protein endoglin with distinct cytoplasmic regions. Eur J Immunol 1993; 23: 2340-2345.

[53] Perez-Gomez E, Eleno N, Lopez-Novoa JM, et al. Characterization of murine S-endoglin isoform and its effects on tumor development. Oncogene 2005; 24: 4450-4461. 
[54] Blanco FJ, Bernabeu C. Alternative splicing factor or splicing factor-2 plays a key role in intron retention of the endoglin gene during endothelial senescence. Aging Cell 2011; 10: 896-907.

[55] Letamendia A, Lastres P, Botella LM, et al. Role of endoglin in cellular responses to transforming growth factor-beta. A comparative study with betaglycan. J Biol Chem 1998; 273: 33011-33019.

[56] Blanco FJ, Grande MT, Langa C, et al. S-endoglin expression is induced in senescent endothelial cells and contributes to vascular pathology. Circ Res 2008; 103: 1383-1392.

[57] Li C, Hampson IN, Hampson L, Kumar P, Bernabeu C, Kumar S. CD105 antagonizes the inhibitory signaling of transforming growth factor beta1 on human vascular endothelial cells. FASEB J 2000; 14: 55-64.

[58] Jerkic $M$, Rodriguez-Barbero $A$, Prieto $M$, et al. Reduced angiogenic responses in adult Endoglin heterozygous mice. Cardiovasc Res 2006; 69: 845-854.

[59] Duwel $A$, Eleno $N$, Jerkic $M$, et al. Reduced tumor growth and angiogenesis in endoglinhaploinsufficient mice. Tumour Biol 2007; 28: 1-8.

[60] Lebrin F, Goumans MJ, Jonker L, et al. Endoglin promotes endothelial cell proliferation and TGFbeta/ALK1 signal transduction. EMBO J 2004; 23: 4018-4028.

[61] Lastres P, Letamendia A, Zhang H, et al. Endoglin modulates cellular responses to TGF-beta 1. J Cell Biol 1996; 133: 1109-1121.

[62] Velasco S, Alvarez-Munoz P, Pericacho $M$, et al. L- and S-endoglin differentially modulate TGFbeta1 signaling mediated by ALK1 and ALK5 in L6E9 myoblasts. J Cell Sci 2008; 121: 913-919.

[63] Blanco FJ, Santibanez JF, Guerrero-Esteo M, et al. Interaction and functional interplay between endoglin and ALK-1, two components of the endothelial transforming growth factor-beta receptor complex. J Cell Physiol 2005; 204: 574-584.

[64] Perez-Gomez E, Del Castillo G, Santibañez JF, et al. The role of the TGF-beta coreceptor endoglin in cancer. Scientific World Journal 2010; 10: 2367-2384.

[65] Cruz-Gonzalez I, Pabon P, Rodriguez-Barbero A, et al. Identification of serum endoglin as a novel prognostic marker after acute myocardial infarction. J Cell Mol Med 2008; 12: 955-961.

[66] Blazquez-Medela AM, Garcia-Ortiz L, Gomez-Marcos MA, et al. Increased plasma soluble endoglin levels as an indicator of cardiovascular alterations in hypertensive and diabetic patients. BMC Med 2010; 8: 86.

[67] Hawinkels L, Kuiper P, Wiercinska E, et al. Matrix metalloproteinase-14 (MT1-MMP)-mediated endoglin shedding inhibits tumor angiogenesis. Cancer Res 2010; 70: 4141-4150.

[68] Castonguay R, Werner ED, Matthews RG, et al. Soluble endoglin specifically binds bone morphogenetic proteins 9 and 10 via its orphan domain, inhibits blood vessel formation, and suppresses tumor growth. J Biol Chem 2011; 286: 30034-30046.

[69] Mitchell D, Pobre EG, Mulivor AW, et al. ALK1-Fc inhibits multiple mediators of angiogenesis and suppresses tumor growth. Mol Cancer Ther 2010; 9: 379-388.

[70] David L, Mallet C, Mazerbourg S, et al. Identification of BMP-9 and BMP-10 as functional activators of the orphan activin receptor-like kinase 1 (ALK1) in endothelial cells. Blood 2007; 109: 1953-1961. 
[71] Fernandez-Ruiz E, St-Jacques S, Bellon T, et al. Assignment of the human endoglin gene (END) to 9q34-->qter. Cytogenet Cell Genet 1993; 64: 204-207.

[72] Graulich W, Nettelbeck DM, Fischer D, et al. Cell type specificity of the human endoglin promoter. Gene 1999; 227: 55-62.

[73] Rius C, Smith JD, Almendro N, et al. Cloning of the promoter region of human endoglin, the target gene for hereditary hemorrhagic telangiectasia type 1. Blood 1998; 92: 4677-4690.

[74] Botella LM, Sanchez-Elsner T, Rius C, et al. Identification of a critical Sp1 site within the endoglin promoter and its involvement in the transforming growth factor-beta stimulation. J Biol Chem 2001; 276: 34486-34494.

[75] Pimanda JE, Chan WY, Donaldson IJ, et al. Endoglin expression in the endothelium is regulated by Fli-1, Erg, and Elf-1 acting on the promoter and a -8-kb enhancer. Blood 2006; 107: 4737-4745.

[76] ten Dijke P, Goumans MJ, Pardali E. Endoglin in angiogenesis and vascular diseases. Angiogenesis 2008; 11: 79-89.

[77] Ota T, Fujii M, Sugizaki T, et al. Targets of transcriptional regulation by two distinct type I receptors for transforming growth factor-beta in human umbilical vein endothelial cells. J Cell Physiol 2002; 193: 299-318.

[78] Scharpfenecker M, van Dinther M, Liu Z, et al. BMP-9 signals via ALK1 and inhibits bFGF-induced endothelial cell proliferation and VEGF-stimulated angiogenesis. J Cell Sci 2007; 120: 964-972.

[79] Sanchez-Elsner T, Botella LM, Velasco B, et al. Endoglin expression is regulated by transcriptional cooperation between the hypoxia and transforming growth factor-beta pathways. J Biol Chem 2002; 277: 43799-43808.

[80] Wang GL, Semenza GL. Purification and characterization of hypoxia-inducible factor 1. J Biol Chem 1995; 270: 1230-1237.

[81] Henry-Berger J, Mouzat K, Baron S, et al. Endoglin (CD105) expression is regulated by the liver X receptor alpha (NR1H3) in human trophoblast cell line JAR. Biol Reprod 2008; 78: 968-975.

[82] Janowski BA, Grogan MJ, Jones SA, et al. Structural requirements of ligands for the oxysterol liver $X$ receptors LXRalpha and LXRbeta. Proc Natl Acad Sci USA 1999; 96: 266-271.

[83] Baranowski M. Biological role of liver X receptors. J Physiol Pharmacol 2008; 59 Suppl 7: 31-55.

[84] Gilbert JS, Gilbert SA, Arany M, et al. Hypertension produced by placental ischemia in pregnant rats is associated with increased soluble endoglin expression. Hypertension 2009; 53: 399-403.

[85] Plosch T, Gellhaus A, van Straten EM, et al. The liver X receptor (LXR) and its target gene ABCA1 are regulated upon low oxygen in human trophoblast cells: a reason for alterations in preeclampsia? Placenta 2010; 31: 910-918.

[86] Mouzat K, Mercier E, Polge A, et al. A common polymorphism in NR1H2 (LXRbeta) is associated with preeclampsia. BMC Med Genet 2011; 12: 145.

[87] Weedon-Fekjaer MS, Johnsen GM, Anthonisen EH, et al. Expression of liver $X$ receptors in pregnancies complicated by preeclampsia. Placenta 2010; 31: 818-824. 
[88] Chandel NS, McClintock DS, Feliciano CE, et al. Reactive oxygen species generated at mitochondrial complex III stabilize hypoxia-inducible factor-1alpha during hypoxia: a mechanism of $\mathrm{O} 2$ sensing. J Biol Chem 2000; 275: 25130-25138.

[89] Al-Gubory KH, Fowler PA, Garrel C. The roles of cellular reactive oxygen species, oxidative stress and antioxidants in pregnancy outcomes. Int J Biochem Cell Biol 2010; 42: 1634-1650.

[90] Aris A, Benali S, Ouellet A, et al. Potential biomarkers of preeclampsia: inverse correlation between hydrogen peroxide and nitric oxide early in maternal circulation and at term in placenta of women with preeclampsia. Placenta 2009; 30: 342-347.

[91] George EM, Granger JP. Recent insights into the pathophysiology of preeclampsia. Expert Rev Obstet Gynecol 2010; 5: 557-566.

[92] Cudmore M, Ahmad S, Al-Ani B, et al. Negative regulation of soluble Flt-1 and soluble endoglin release by heme oxygenase-1. Circulation 2007; 115: 1789-1797.

[93] Wang Y, Walsh SW. Increased superoxide generation is associated with decreased superoxide dismutase activity and mRNA expression in placental trophoblast cells in pre-eclampsia. Placenta 2001; 22: 206-212.

[94] Wang Y, Walsh SW. Antioxidant activities and mRNA expression of superoxide dismutase, catalase, and glutathione peroxidase in normal and preeclamptic placentas. J Soc Gynecol Investig 1996; 3: 179-184.

[95] Tam Tam KB, Lamarca B, Arany M, et al. Role of reactive oxygen species during hypertension in response to chronic antiangiogenic factor (sFlt-1) excess in pregnant rats. Am J Hypertens 2011; 24: $110-113$.

[96] Wakatsuki A, Ikenoue N, Okatani Y, et al. Lipoprotein particles in preeclampsia: susceptibility to oxidative modification. Obstet Gynecol 2000; 96: 55-59.

[97] Qiu C, Phung TT, Vadachkoria S, et al. Oxidized low-density lipoprotein (Oxidized LDL) and the risk of preeclampsia. Physiol Res 2006; 55: 491-500.

[98] Pavan L, Hermouet A, Tsatsaris V, et al. Lipids from oxidized low-density lipoprotein modulate human trophoblast invasion: involvement of nuclear liver X receptors. Endocrinology 2004; 145: 45834591.

[99] Schroepfer GJ. Oxysterols: modulators of cholesterol metabolism and other processes. Physiol Rev 2000; 80: 361-554.

[100] Redman CW, Sargent IL. Placental stress and pre-eclampsia: a revised view. Placenta 2009; 30 Suppl A: S38-42.

[101] Cindrova-Davies T. Gabor Than Award Lecture 2008: pre-eclampsia - from placental oxidative stress to maternal endothelial dysfunction. Placenta 2009; 30 Suppl A: S55-65.

[102] Tskitishvili E, Sharentuya N, Temma-Asano K, et al. Oxidative stress-induced S100B protein from placenta and amnion affects soluble Endoglin release from endothelial cells. Mol Hum Reprod 2010; 16: 188-199.

[103] Kaitu'u-Lino TJ, Palmer KR, Whitehead CL, et al. MMP-14 is expressed in preeclamptic placentas and mediates release of soluble endoglin. Am J Pathol 2012; 180: 888-894. 
[104] Munoz-Najar UM, Neurath KM, Vumbaca F, et al. Hypoxia stimulates breast carcinoma cell invasion through MT1-MMP and MMP-2 activation. Oncogene 2006; 25: 2379-2392.

[105] Valbuena-Diez AC, Blanco FJ, Oujo B, et al. Oxysterol-induced soluble endoglin release and its involvement in hypertension. Circulation 2012; 126: 2612-2624.

[106] Nishida C, Kusubata K, Tashiro Y, et al. MT1-MMP plays a critical role in hematopoiesis by regulating HIF-mediated chemokine/cytokine gene transcription within niche cells. Blood 2012; 119: 5405-5416.

[107] Gu Y, Lewis DF, Wang Y. Placental productions and expressions of soluble endoglin, soluble fmslike tyrosine kinase receptor-1, and placental growth factor in normal and preeclamptic pregnancies. J Clin Endocrinol Metab 2008; 93: 260-266.

[108] Aoki Y, Yamamoto T, Fumihisa C, et al. Effect on the production of soluble endoglin from human choriocarcinoma cells by preeclampsia sera. Am J Reprod Immunol 2012; 67: 413-420.

[109] Zhou CC, Irani RA, Zhang Y, et al. Angiotensin receptor agonistic autoantibody-mediated tumor necrosis factor-alpha induction contributes to increased soluble endoglin production in preeclampsia. Circulation 2010; 121: 436-444.

[110] George EM, Cockrell K, Aranay M, et al. Induction of heme oxygenase 1 attenuates placental ischemia-induced hypertension. Hypertension 2011; 57: 941-948.

[111] Cudmore MJ, Ahmad S, Sissaoui S, et al. Loss of Akt activity increases circulating soluble endoglin release in preeclampsia: identification of inter-dependency between Akt-1 and heme oxygenase-1. Eur Heart J 2012; 33: 1150-1158.

[112] Luo X, Yao ZW, Qi HB, et al. Gadd45alpha as an upstream signaling molecule of p38 MAPK triggers oxidative stress-induced sFlt-1 and sEng upregulation in preeclampsia. Cell Tissue Res 2011; 344: 551-565.

[113] Xiong Y, Liebermann DA, Tront JS, et al. Gadd45a stress signaling regulates sFlt-1 expression in preeclampsia. J Cell Physiol 2009; 220: 632-639.

[114] Conrad KP, Miles TM, Benyo DF. Circulating levels of immunoreactive cytokines in women with preeclampsia. Am J Reprod Immunol 1998; 40: 102-111.

[115] LaMarca B, Parrish MR, Wallace K. Agonistic autoantibodies to the angiotensin II type I receptor cause pathophysiologic characteristics of preeclampsia. Gend Med 2012; 9: 139-146.

[116] Jain A, Olovsson M, Burton GJ, et al. Endothelin-1 induces endoplasmic reticulum stress by activating the PLC-IP(3) pathway: implications for placental pathophysiology in preeclampsia. Am J Pathol 2012; 180: 2309-2320.

[117] Overall CM, Kleifeld O. Tumour microenvironment - opinion: validating matrix metalloproteinases as drug targets and anti-targets for cancer therapy. Nat Rev Cancer 2006; 6: 227-239.

[118] Nakada M, Miyamori H, Yamashita J, et al. Testican 2 abrogates inhibition of membrane-type matrix metalloproteinases by other testican family proteins. Cancer Res 2003; 63: 3364-3369.

[119] Nakada M, Yamada A, Takino T, et al. Suppression of membrane-type 1 matrix metalloproteinase (MMP)-mediated MMP-2 activation and tumor invasion by testican 3 and its splicing variant gene product, N-Tes. Cancer Res 2001; 61: 8896-8902. 
[120] Devy L, Huang L, Naa L, et al. Selective inhibition of matrix metalloproteinase-14 blocks tumor growth, invasion, and angiogenesis. Cancer Res 2009; 69: 1517-1526.

[121] Li Z, Zhang Y, Ying Ma J, Kapoun AM, et al. Recombinant vascular endothelial growth factor 121 attenuates hypertension and improves kidney damage in a rat model of preeclampsia. Hypertension 2007; 50: 686-692.

[122] Kumasawa K, Ikawa M, Kidoya H, et al. Pravastatin induces placental growth factor (PGF) and ameliorates preeclampsia in a mouse model. Proc Natl Acad Sci USA 2011; 108: 1451-1455. 
FIGURE LEGENDS

Fig. 1. A) Schematic representation of L-Endoglin structure. Endoglin is a disulfide linked homodimer whose extracellular region contains a Zona Pellucida (ZP) domain and an Orphan domain. The position of the consensus integrin-binding RGD motif and PDZ-binding motif are indicated. B) An alternative splicing mechanism generates L-endoglin and S-endoglin. The endoglin gene, containing 15 exons, undergoes alternative splicing leading to two different mRNA coding for L-endoglin and S-endoglin. Retention of the intron between exon \#13 and exon \#14 gives rise to S-endoglin. Translation of these transcripts results in two distinct endoglin isoforms that differ from each other in the amino acid composition of their cytoplasmatic tail. The PDZ motif is present in the L-endoglin form, but not in Sendoglin.

Fig. 2. All three endoglin forms regulate TGF-beta signaling pathway in endothelial cells. L-endoglin (LEng) and S-endoglin (S-Eng) are membrane isoforms able to bind TGF-beta family members. L-Endoglin promotes the ALK1 mediated signaling pathway, whereas S-Endoglin cooperates with the ALK5 signaling pathway. The soluble form of endoglin (sEng), consequence of the proteolytic cleavage of the membrane isoforms by MT1-MMP (MMP-14), inhibits TGF-beta signaling by preventing ligand binding to the membrane receptor.

Fig. 3. A) Preeclamptic placenta is characterized by narrow spiral arteries that carry limited blood flow causing a hypoxic condition. B) Hypoxia signaling pathway. Hypoxia upregulates endoglin expression via HIF-1alpha, which migrates into the nucleus where it binds to HRE in the endoglin promoter and cooperates with other transcription factors such as Sp1 or Smads. Moreover, HIF-1alpha stimulates TGF-beta3 gene expression and in turn, TGF-beta signaling induces endoglin expression via Smad3.

Fig. 4. Overview on the major mechanisms responsible for membrane endoglin (mEndoglin) overexpression and soluble endoglin (sEng) shedding in preeclampsia. 


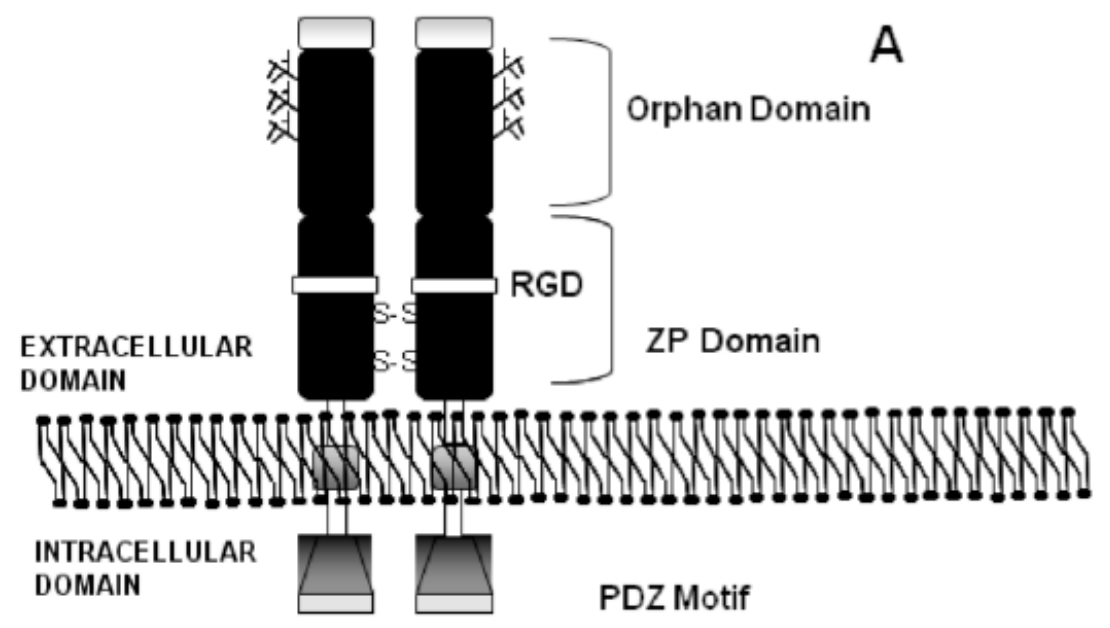

B

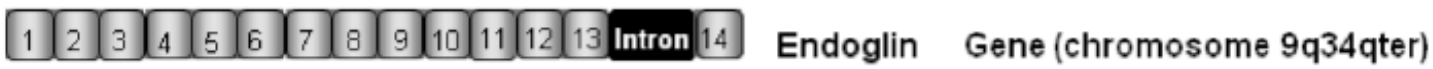

$\downarrow$ Transcription

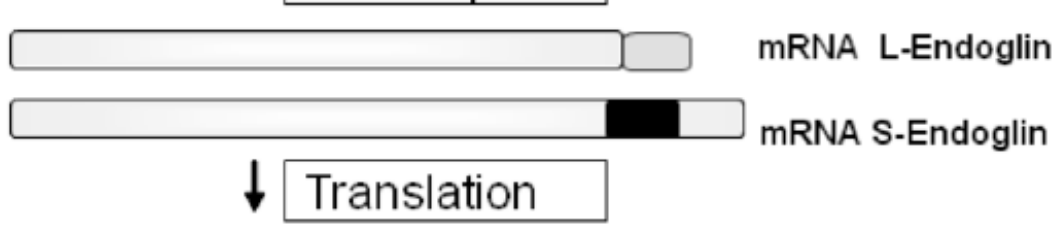

LEndoglin: YIYYSHTRSPSKREPWAVAAPASSESSSTNHSIGSTOSTPCSTSM

L-Endoglin: YIYSHTRSPSKREPWAVAAPASSESSSTNHSIGSTQSTPCSTSMA

S-Endoglin: YIYSHTREYPRPPQ

PDZ Motif

Cytoplasmatic tail

Figure 1 


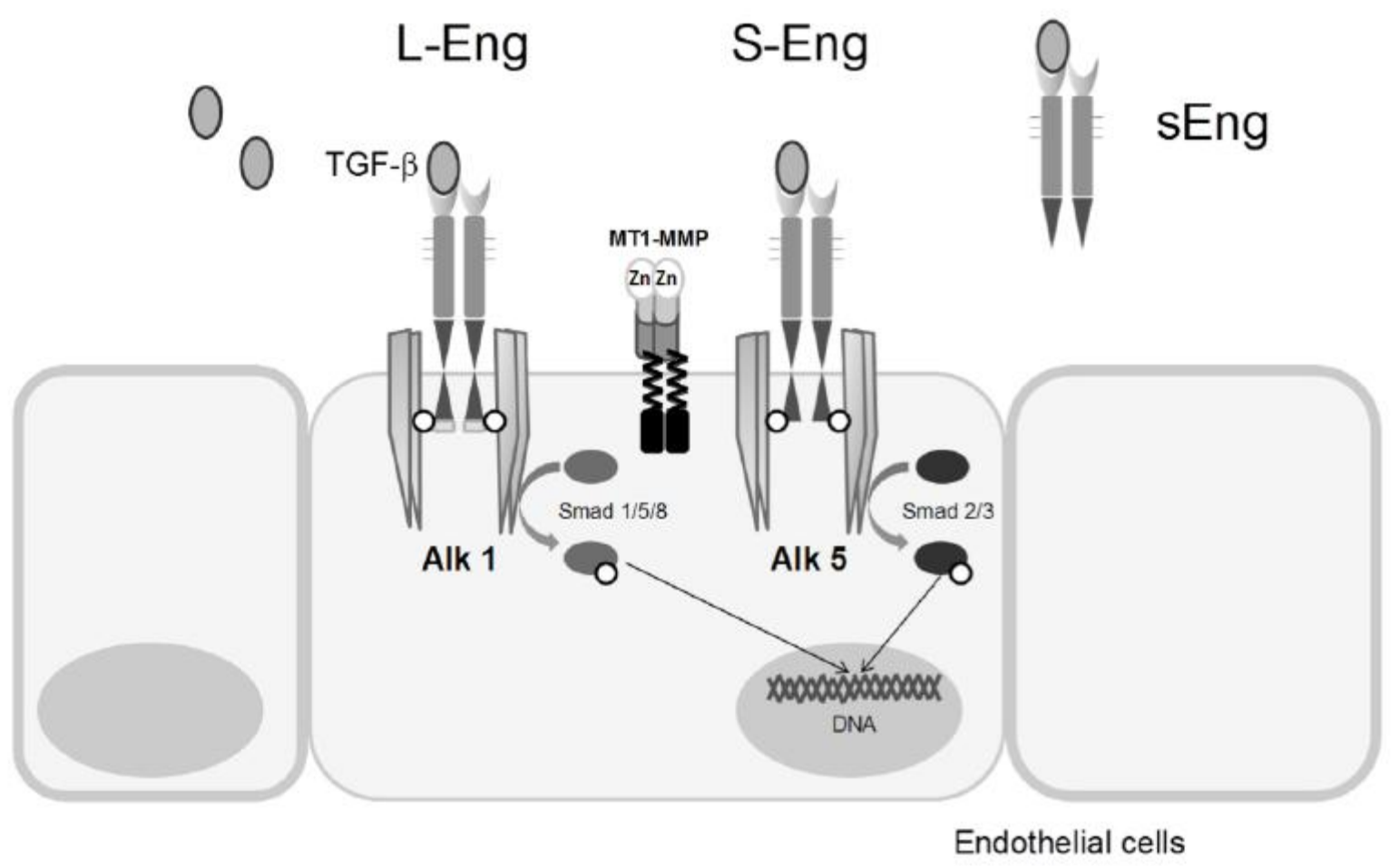

Figure 2 


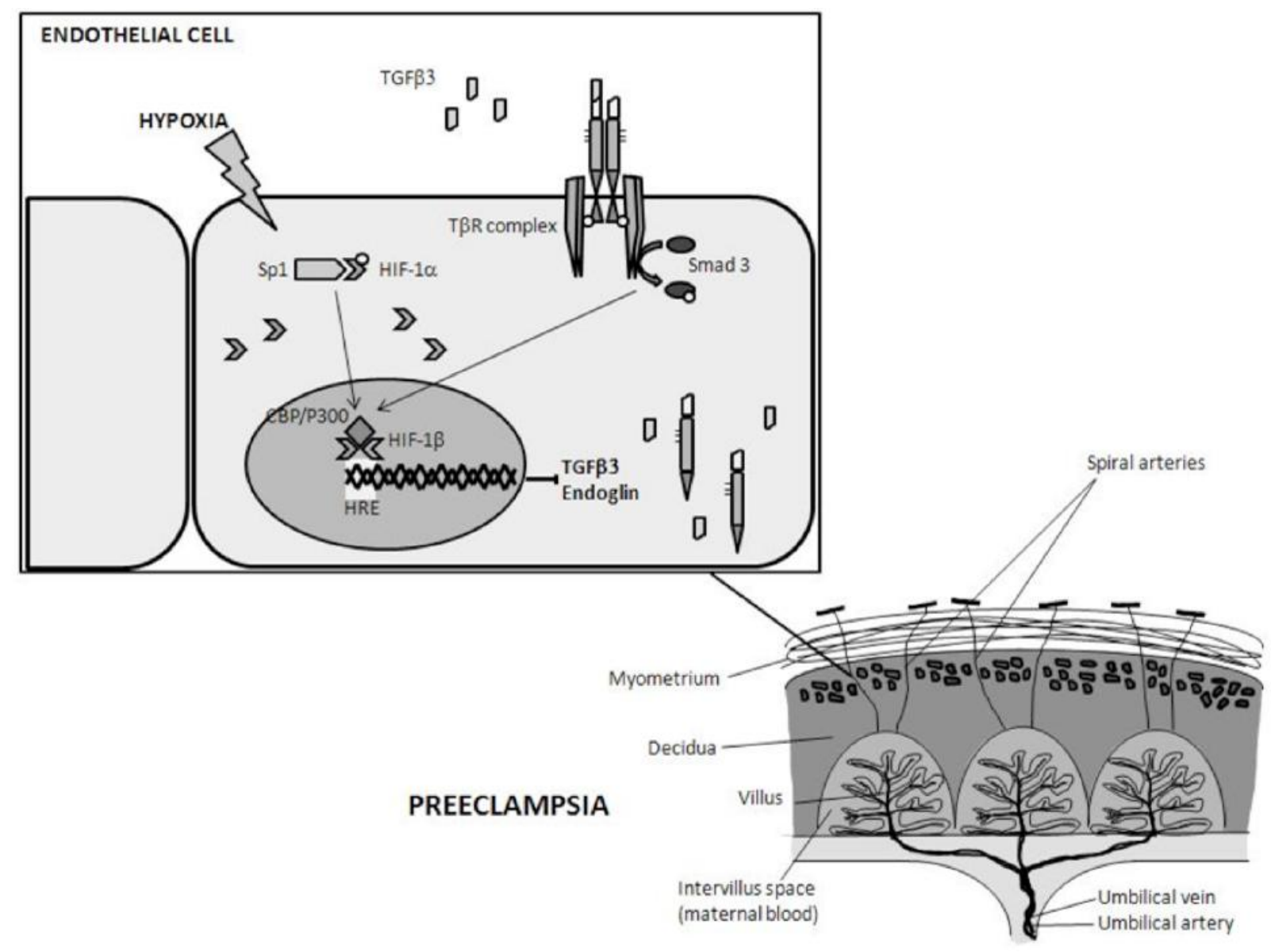

Figure 3 


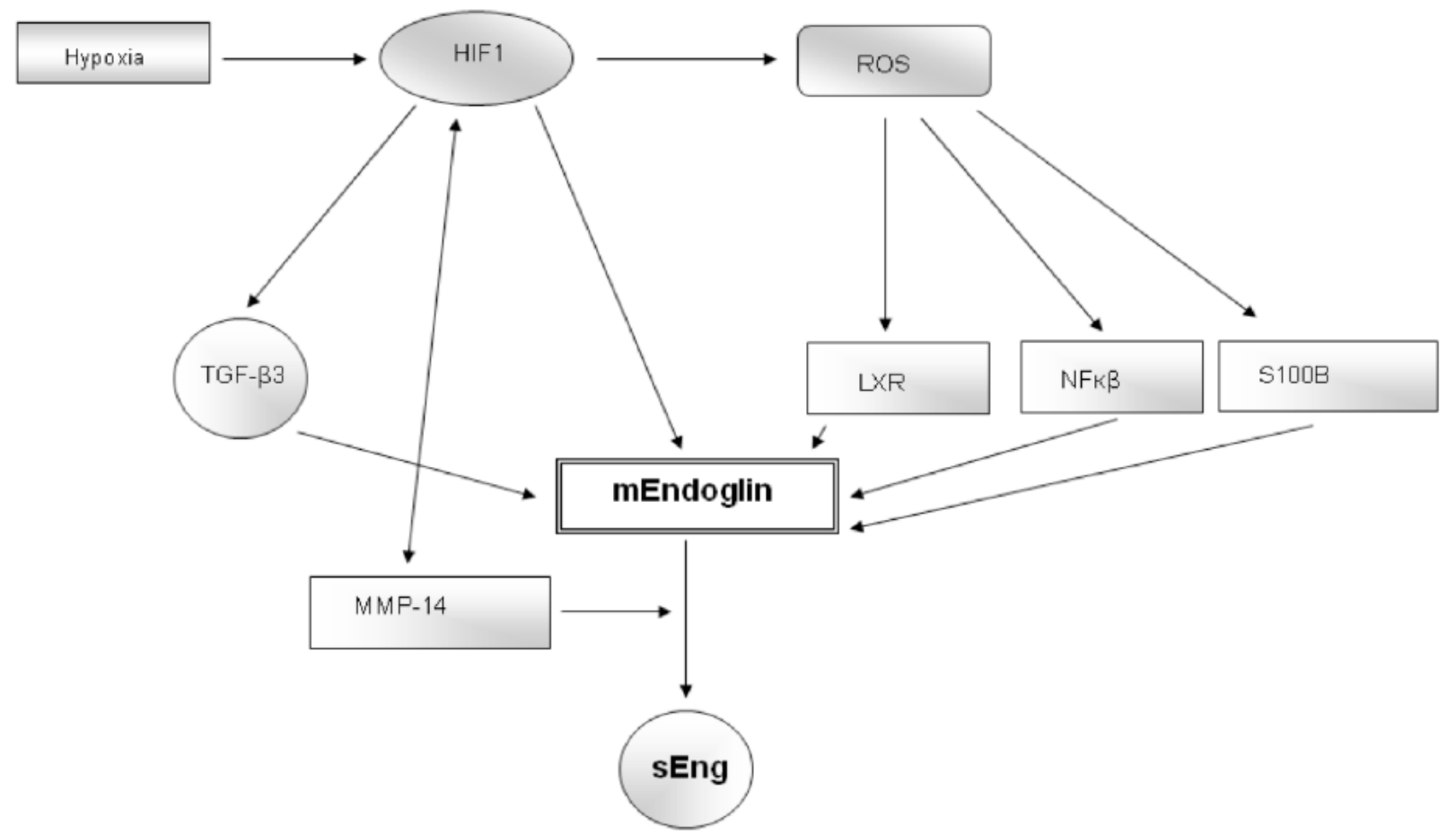

Figure 4 